\section{OP0220 RANDOMIZED, DOUBLE-BLIND, GLOBAL CLINICAL TRIAL TO EVALUATE EQUIVALENCE OF CHS-1420 TO ADALIMUMAB IN PATIENTS WITH PSORIASIS AND PSORIATIC ARTHRITIS}

J. O'Dell ${ }^{1}$, A. Kivitz ${ }^{2}$, K. Papp ${ }^{3}$, C. Leonardi ${ }^{4}$, K. Jensen ${ }^{5}$, H. Tang ${ }^{5}$, B. Finck ${ }^{5}$ on behalf of The PsOsim Study Group. ${ }^{1}$ University of Nebraska Medical Center, Omaha, NE; ${ }^{2}$ Altoona Center for Clinical Research, Duncansville, PA, United States; ${ }^{3}$ K. Papp Clinical Research, Waterloo, Ontario, Canada: ${ }^{4}$ Central Dermatology, St. Louis, MO; ${ }^{5}$ Coherus BioSciences, Redwood City, CA, United States

Background: CHS-1420 is being developed as a proposed biosimilar to adalimumab for the treatment of rheumatoid arthritis, plaque psoriasis ( $\mathrm{PsO}$ ), and other auto-immune diseases.

Objectives: This phase 3, randomized, double-blind, active-controlled, multicenter study evaluated the equivalence of CHS-1420 to adalimumab in patients with active, moderate-severe, chronic plaque $\mathrm{PsO}$, including patients with psoriatic arthritis (PsA).

Methods: Male and female patients (aged $>18$ years) were randomized to CHS-1420 or adalimumab. Patients received $40 \mathrm{mg} \times 2$ on Day 0 and then $40 \mathrm{mg}$ every other week (QOW) by subcutaneous injection. To establish the equivalence of CHS-1420 to adalimumab, the $95 \% \mathrm{Cl}$ of the treatment difference for the primary endpoint, PASI75 at Week 12, had to be within pre-specified equivalence margins of $\pm 15 \%$. The 55 -week study is ongoing, and blinded efficacy data at Week 12 and safety data through Week 16 are available. The study was not powered for statistical analysis of the PsA subgroup. Patients with PsA were evaluated based on change in the Health Assessment Questionnaire - Disability Index (HAQ-DI) and highly sensitive C-reactive protein (hs-CRP).

Results: The full analysis population for the primary efficacy endpoint consisted of 545 patients (mean age 43.9 years), with 274 and 271 in Group A and Group B, respectively. The mean BMI was $29.6 \mathrm{~kg} / \mathrm{m}^{2}$, and $72.3 \%$ were male. At Week 12 , the proportion of patients achieving a PASI75 from Baseline was $77.7 \%$ in Group A and $74.5 \%$ in Group B. The $95 \% \mathrm{Cl}$ of the treatment difference [-3.63, $10.28]$ was within the pre-specified equivalence margin $[-15.0,15.0]$. Sensitivity analyses supported equivalence of the two treatments.

PsA was present in $65(23.7 \%)$ and 61 (22.5\%) patients in Group A and Group B, respectively. A PASI75 was achieved by $81.5 \%$ and $77.0 \%$ of patients with PsA in Group A and Group B, respectively, at Week 12. Mean HAQ-DI scores decreased from Baseline by 0.6 and $0.7(95 \% \mathrm{Cl}:-0.3,0.3)$ at Week 12 in Group A and Group B, respectively. Mean hs-CRP (mg/L) decreased from Baseline by 8.9 and 6.3 at Week 12 in Group A and Group B, respectively.

In the safety population $(n=545)$, adverse events were reported in $48.5 \%$ and $45.0 \%$ of patients, in Group A and Group B, respectively, through Week 16. Serious adverse events were reported in $1.1 \%$ and $2.2 \%$ of patients in Group A and Group B, respectively, through Week 16, and none were judged by the investigator to be related to treatment. The most common ( $\geq 5 \%$ of patients) adverse events were nasopharyngitis and upper respiratory tract infection.

Conclusions: This randomized, double-blind, global clinical trial demonstrated the equivalence of CHS-1420 to adalimumab in the treatment of chronic PsO. Both study drugs were well tolerated. Patients with PsA showed improvement with both study drugs.

Disclosure of Interest: J. O'Dell Consultant for: Coherus BioSciences, A. Kivitz: None declared, K. Papp Consultant for: 3M, Abbott/AbbVie, Akesis, Akros, Allergan, Amgen, Alza, Anacor, Applied Molecular Evolution, Astellas, Baxter, Bayer, Boehringer Ingelheim, Celgene, Celtic, Centocor, Cipher, Coherus, Dermira, Dow Pharma, Eli Lilly, Forward Pharma, Funxional Therapeutics, Galderma, Genentech, Genet, GSK, Isotechnika, Janssen, Janssen Biotech (Centocor), Kyowa Hakko Kirin, Merck, Merck-Serono, Novartis, Pfizer, C. Leonardi: None declared, K. Jensen Shareholder of: Coherus BioSciences, Employee of: Coherus BioSciences, H. Tang Shareholder of: Coherus BioSciences, Employee of: Coherus BioSciences, B. Finck Shareholder of: Coherus BioSciences, Employee of: Coherus BioSciences

DOI: 10.1136/annrheumdis-2017-eular.2490

\section{OP0221 RADIOGRAPHIC PROGRESSION OF STRUCTURAL JOINT DAMAGE IN PATIENTS WITH ACTIVE PSORIATIC ARTHRITIS TREATED WITH IXEKIZUMAB OVER 52 WEEKS}

D. van der Heijde ${ }^{1}$, M. Okada ${ }^{2}$, C. Lee ${ }^{3}$, C.L. Shuler ${ }^{3}$, S. Rathmann ${ }^{3}$,
C.-Y. Lin ${ }^{3}$, P. Mease ${ }^{4}{ }^{1}$ Leiden University Medical Centre, Leiden, Netherlands; ${ }^{2}$ St. Luke's international Hospital, Tokyo, Japan; ${ }^{3}$ Eli Lilly and Company, Indianapolis; ${ }^{4}$ Swedish Medical Center and University of Washington, Seattle, United States

Background: Ixekizumab (IXE), an anti-interleukin-17A monoclonal antibody, was shown to be superior to placebo (PBO) in clinical responses and inhibiting the progression of structural joint damage in patients (pts) with psoriatic arthritis (PsA) treated for 24 weeks (wks)

Objectives: To assess progression of structural joint damage in PsA pts with IXE for up to 52 wks.

Methods: Biologic DMARD-naïve pts with active PsA ( $\mathrm{N}=417)$ entered into SPIRIT-P1 (NCT01695239), a double-blind phase 3 trial. Pts must have had $\geq 1$ joint erosion on the hand and foot $\mathrm{x}$-rays confirmed by central reading or had a C-reactive protein level $>6 \mathrm{mg} / \mathrm{L}$ at screening. $417 \mathrm{pts}$ were randomized to IXE $80 \mathrm{mg}$ every 2 wks (Q2W; $\mathrm{N}=103$ ) or 4 wks (Q4W; $\mathrm{N}=107$ ) following a 160 $\mathrm{mg}$ initial dose, $\mathrm{PBO}(\mathrm{N}=106)$, or adalimumab $40 \mathrm{mg}$ every 2 wks (ADA; active reference arm; $\mathrm{N}=101$ ) for 24 wks. In the Extension Period (EXT: Wks 24-52), PBO and ADA pts were re-randomized (1:1) to IXEQ2W or IXEQ4W at Wk 16 (inadequate responders) or Wk 24; ADA pts underwent a washout prior to IXE treatment. All pts were assessed for structural joint damage using the van der Heijde modified PsA Total Sharp Score (mTSS, 0-528 scale). X-rays at Wks 0, 24 and 52 were scored independently by 2 readers blinded to timepoint and clinical data (average of readers). mTSS was excluded from the pre-specified analysis if the radiograph was taken after the scheduled visit date. In a post-hoc analysis, mTSS from a radiograph taken after the scheduled visit date was interpolated and considered as observed data. Any missing data at Wk 52, in either presentation, were imputed using a linear extrapolation if they had at least 1 post-baseline value.

Results: Pts had active PsA at Week 0 (Table). 381 pts (91.3\%) entered the EXT with $374(98.2 \%)$ having radiographs collected during the EXT. Wk 52 mean (SD) mTSS change from baseline were $0.54(2.11)$ and $0.09(1.0)$ for pts randomized to IXEQ4W and IXEQ2W at baseline, respectively. Similar changes at Wk 52 were obtained with the post-hoc analysis (Table). The majority of IXEQ2W or IXEQ4W pts exhibited no structural progression through 1 year of IXE treatment (Figure). In pts who switched from PBO or ADA to IXE, Wk 52 mean change from baseline mTSS values scores ranged from -0.03 to 0.41 (Table).

Observed mTSS Change from Baseline Values at Week 52

Cumulative Distribution Plot

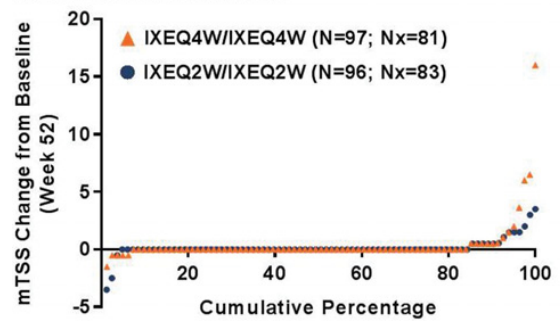

$\mathrm{N}=\mathrm{EXT}$ patients; $\mathrm{NX}=\mathrm{Pts}$ with baseline and Wk 52 radiograph assessments. mTSS values from radiographs taken after the Wk 52

Conclusions: Over a 52 wk period, minimal changes in mTSS were observed in PsA pts entering the EXT and treated with IXEQ2W or IXEQ4W.

References:

[1] Mease P et al. 2017 ARD 76(1):79.

Disclosure of Interest: D. van der Heijde Consultant for: AbbVie, Amgen, Astellas, AstraZeneca, BMS, Boeringer Ingelheim, Celgene, Daiichi, Eli Lilly and Company, Galapagos, Gilead, Janssen, Merck, Novartis, Pfizer, Regeneron, Roche, Sanofi, UCB, M. Okada Grant/research support from: Eli Lilly and Company, Consultant for: Eli Lilly and Company, Speakers bureau: Santen Pharmaceutical, Mitsubishi Tanabe Pharma, Pfizer, Abbott Japan, C. Lee Shareholder of: Eli Lilly and Company, Employee of: Eli Lilly and Company, C. Shuler Shareholder of: Eli Lilly and Company, Employee of: Eli Lilly and Company, S. Rathmann Shareholder of: Eli Lilly and Company, Employee of: Eli Lilly and Company, C.-Y. Lin Shareholder of: Eli Lilly and Company, Employee of: Eli Lilly and Company, P. Mease Grant/research support from: AbbVie, Amgen, Bristol Myers

Abstract OP0221 - Table 1. Radiographic Progression of Structural Joint Damage for EXT Pts

\begin{tabular}{|c|c|c|c|c|c|c|}
\hline & $\mathrm{PBO} / \mathrm{XXQ} 4 \mathrm{~W}(\mathrm{~N}=45)$ & $\mathrm{PBO} / \mathrm{IXEQ2W}(\mathrm{N}=46)$ & ADA/IXEQ4W $(\mathrm{N}=49)$ & ADA/IXEQ2W $(\mathrm{N}=48)$ & IXEQ4W/IXEQ4W (N=97) & IXEQ2W/IXEQ2W ( $\mathrm{N}=96)$ \\
\hline \multicolumn{7}{|c|}{ Baseline (Week 0) Disease Characteristics, Mean (SD) } \\
\hline mTSS & $11.5(15.5)$ & $24.5(37.3)$ & $15.6(24.3)$ & $15.4(30.2)$ & $19.6(33.3)$ & $15.2(29.1)$ \\
\hline Tender Joint Count & $18.5(11.6)$ & $19.2(14.0)$ & $18.8(11.9)$ & $18.8(12.8)$ & $20.8(13.6)$ & $21.3(13.8)$ \\
\hline Swollen Joint Count & $9.6(6.2)$ & $10.7(7.1)$ & $10.1(7.4)$ & $9.6(5.5)$ & $11.0(7.3)$ & $12.2(7.3)$ \\
\hline \multicolumn{7}{|l|}{ mTSS, Pre-Specified, Mean (SD) } \\
\hline \multirow[t]{2}{*}{ Week 52 Change from Baseline } & $\mathrm{n}=31$ & $\mathrm{n}=37$ & $\mathrm{n}=36$ & $\mathrm{n}=34$ & $\mathrm{n}=80$ & $\mathrm{n}=80$ \\
\hline & $0.27(0.8)$ & $0.41(0.8)$ & $0.32(1.0)$ & $-0.03(0.4)$ & $0.54(2.1)$ & $0.09(1.0)$ \\
\hline \multicolumn{7}{|l|}{ mTSS, Post-Hoc, Mean (SD) } \\
\hline \multirow[t]{2}{*}{ Week 52 Change from Baseline } & $\mathrm{n}=44$ & $\mathrm{n}=45$ & $\mathrm{n}=47$ & $\mathrm{n}=45$ & $\mathrm{n}=97$ & $\mathrm{n}=96$ \\
\hline & $0.25(0.8)$ & $0.51(1.1)$ & $0.24(0.9)$ & $0.06(0.5)$ & $0.47(1.9)$ & $0.09(0.9)$ \\
\hline
\end{tabular}

